\title{
Low birth weight and health expenditures from birth to late adolescence
}

\author{
Michael Hummer • Thomas Lehner • \\ Gerald Pruckner
}

Received: 22 August 2012/Accepted: 20 February 2013/Published online: 2 April 2013

(c) Springer-Verlag Berlin Heidelberg 2013

\begin{abstract}
Objectives The aim of this paper is to analyze the impact of low birth weight (LBW) and very low birth weight (VLBW) on health care utilization in childhood and early adolescence.

Data/methods Using Austrian health insurance administrative panel data linked to the Austrian birth register, we estimate the effects of LBW and VLBW in comparison to normal birth weight (NBW) on the number of days spent in the hospital and on expenditures for medical assistance and medical drugs among children and young adults between birth and 21 years of age. To account for the time-invariant heterogeneity of mothers, we control for sibling fixed effects.

Results We find that, in comparison to their NBW counterparts, LBW infants spend more days hospitalized and more is spent on medical drugs (particularly on antiinfectives) for them in their first year of life. Although the absolute differences in health service utilization between NBW and LBW groups diminish over time, LBW newborns still spend more days hospitalized, and their medical drug and medical assistance expenses are significantly higher in early childhood. During compulsory schooling, we observe a shift toward diseases of the nervous system
\end{abstract}

Electronic supplementary material The online version of this article (doi:10.1007/s10198-013-0468-1) contains supplementary material, which is available to authorized users.

M. Hummer $(\varangle) \cdot$ T. Lehner $\cdot$ G. Pruckner Department of Economics, Johannes Kepler University Linz, Altenberger Straße 69, 4040 Linz, Austria

e-mail: michael.hummer@jku.at

M. Hummer · G. Pruckner

The Austrian Center for Labor Economics and the Analysis of the Welfare State, Linz, Austria and mental and behavioral disorders among children born with LBW. Some of these effects persist until early adulthood.

Conclusions We argue for further counseling efforts for expectant mothers on the determinants and risk factors of LBW. Moreover, pre-school screenings especially tailored to LBW infants with a particular focus on mental health and behavioral disorders can be easily integrated in the existing postnatal mother-child care program in Austria to mitigate the consequences of negative conditions during pregnancy.

Keywords Low birth weight · Health expenditures . Sibling fixed effects

JEL Classification $\mathrm{I} 10 \cdot \mathrm{I} 12 \cdot \mathrm{I} 18$

\section{Introduction}

Low birth weight (LBW) among babies has been established as a leading indicator of their physical and cognitive development during pregnancy. The argument is that beyond genetic predisposition, the behavior of expectant mothers and external (environmental) influences in utero may have persistent and negative effects on children. These negative impacts on the fetus are reflected by LBW, which has a critical threshold of less than 2,500 g. ${ }^{1}$ The major finding of the (predominantly Anglo-Saxon) health economics literature is that LBW babies have worse short- and

\footnotetext{
$\overline{1}$ The World Health Organization (WHO) uses the incidence rate of babies with LBW as an indicator of a multifaceted public health problem (see the WHO Statistical Information System, http://www. who.int/whosis/indicators/compendium/2008/2bwn/en).
} 
long-term outcomes: (1) LBW entails high direct neonatal treatment costs, (2) LBW babies have a higher probability of infant mortality, (3) there is evidence of lower educational attainment and labor market outcomes among those with LBW, and (4) LBW may cause negative long-term health consequences. ${ }^{2}$ The relevance of the negative effects of LBW on short- and long-term outcomes to health policy is obvious, since the issue is closely connected to the questions of whether and to what extent socio-medical interventions during pregnancy would be useful, not only from a medical but also from an economic perspective.

Empirical economic and epidemiological research on birth weight is found in two different strands of literature. One branch analyzes birth weight as the output of prenatal health factors with a focus on maternal behavior during pregnancy (see Almond et al. [5] and the literature cited therein). The second strand of literature focuses on birth weight as a proxy of a newborn's initial endowment of health capital. The upshot of this empirical research is that LBW has persistent and negative long-term effects on economic, educational, and health outcomes. ${ }^{3}$

The available empirical evidence is often cross sectional, and the presented association between LBW and the costs it imposes upon society may be biased by omitted variables, such as genetics. Consequently, a series of recent papers have controlled for observed and unobserved heterogeneity among mothers by exploiting within-twin variation in birth weight. Behrman and Rosenzweig [8] use data on female monozygotic twins born between 1936 and 1955 from the Minnesota Twin Registry and find that an increase in fetal growth has significantly positive effects on educational attainment, wages, and adult height. They also show that twin fixed-effects estimates are quantitatively larger than those from cross-section specifications. Similarly, Almond et al. [5] analyze twin pairs born in the US between 1983 and 2000. They find short-term health effects of LBW that are a fraction of those found in more conventional cross-sectional evidence. In cross-section specifications, an increase in birth weight by one standard deviation is associated with an increase in Apgar scores, a reduction in infant mortality, a reduction in assisted ventilator use after birth, and a decrease in hospital costs, all by $0.25-0.51$ standard deviations. In contrast, the corresponding figures are 0.01-0.08 standard deviations for the

\footnotetext{
${ }^{2}$ Currie [13] provides an excellent literature review on the links between the health of children and their future education or income with a particular focus on the role of birth weight. For an example of a paper discussing the effects of LBW on future health, see Kramer [21].

${ }^{3}$ For predominantly cross-sectional evidence on the effects of LBW in non-economic disciplines, see, for instance, the surveys by Pojda and Kelley [27], Ashdown-Lambert [6], and Aarnoudse-Moens et al. [1].
}

twin specifications. In their analysis of twin births using the 1995-1997 US Matched Multiple Birth Data Set, Conley et al. [12] provide estimates of similar magnitudes of the effects of birth weight on infant mortality. The authors further show that the relative impacts of genes and prenatal environment vary by the length of gestation. The intrapair variation in the prenatal environment seems to be particularly important in determining the negative association between birth weight and infant mortality in pregnancies with gestation lengths of under 37 weeks.

Black et al. [10] provide influential evidence on both short- and long-term outcomes of LBW. The authors use within-twin variation in a rich administrative data set from Norway and find significantly negative impacts of LBW on adult height, IQ, and educational attainment. They estimate that a 7.5 percent increase in birth weight would increase adult height by $0.2 \mathrm{~cm}$, the stanine IQ score by 0.05 , and fulltime earnings by 1 percent. ${ }^{4}$ Similarly, Oreopoulos et al. [26] use sibling and twin variation in Canadian data and find that LBW is a strong predictor of high school completion and welfare receipt and duration. In another recent study based on twin data from Californian birth records and on data for the US Early Childhood Longitudinal Study Birth Cohort, Royer [28] finds generally small effects of birth weight on educational attainment, later pregnancy complications, and the birth weight of the next generation.

Previous studies that use sibling fixed effects include those by Bennet and Conley [9], who use US panel data and find that LBW results in lower educational attainment after correcting for other factors, and by Currie and Moretti [14], who found a 50 percent higher probability that a child had LBW if the mother had LBW in a review of California birth certificate data. Moreover, the authors find, after controlling for grandmother fixed effects, that being born with LBW has significant and negative effects on later socioeconomic achievements. For a more recent contribution including sibling fixed effects, see Johnson and Schoeni [20], who find that LBW increased the probability of failure to complete high school and decreased labor market participation and wages.

In this article, we analyze the development of LBW newborns' health care utilization during their early years of life. In particular, we use Austrian administrative health service data linked to the Austrian birth register to study the impact of LBW and VLBW (this latter is defined as birth weight less than $1,500 \mathrm{~g}$ ) on health outcomes during childhood and early adulthood. The article contributes to the literature on birth weight as an initial endowment for future health capital in several respects: (1) the analysis is

\footnotetext{
4 The twin fixed-effects estimates of LBW on short-term outcomes such as Apgar scores and infant mortality obtained by these researchers are, however, quantitatively very small.
} 
not restricted to outcomes that are only available at a particular point in time. We observe health-related outcomes for individuals between birth and 21 years of age for periods of up to 5 years. (2) The exceptionally detailed data on health-care consumption provided by a mandatory statelevel sickness fund include days hospitalized (and admission diagnoses ${ }^{5}$ ), ambulatory doctor visits, and medical drug consumption. Moreover, the consumption of medical drugs is classified according to the Anatomical Therapeutic Chemical System (ATC) of the WHO. Given that we also observe the medical specialties of resident doctors seen by the children in the sample, we analyze in detail the medical conditions from which children born with LBW are more likely to suffer in their first 21 years of life. ${ }^{6}$

The rest of the article is organized as follows: "Institutional setting" discusses the institutional setting of the Austrian health system with a focus on pre- and postnatal maternal service utilization. "Data" presents the data and descriptive statistics. "Methods" outlines the empirical strategy. "Empirical results" presents the empirical results. "Discussion" includes a discussion of the results, and "Conclusions" concludes the article.

\section{Institutional setting}

Austria has a Bismarckian-type social health insurance system, with every resident being covered by mandatory health insurance. The assignment of employees and their dependents to a sickness fund depends on the employers' location and the type of occupation. Therefore, sickness funds cannot be freely chosen by the insurant. The sickness fund covers all costs associated with sickness and maternity and the utilization of both inpatient and outpatient health-care services. Therefore, health service utilization is not restricted by financial constraints. ${ }^{7}$ Although there is no mandatory gatekeeping system in the Austrian outpatient sector, it is recommended that patients first visit their GPs before consulting medical specialists. ${ }^{8}$

\footnotetext{
5 Diseases are coded according to ICD-10 of the International Statistical Classification of Diseases and Related Health Problems.

${ }^{6}$ Concerning the structure of the data, the study by Currie et al. [16] is the most similar to ours. The authors use public health insurance records of persons born in the Canadian province of Manitoba between 1979 and 1987. These data, which are available for at least 20 years after birth, are linked with administrative records on education and welfare receipt. However, the data do not include information on the consumption of medical drugs, and the focus of the article is on the health problems in early childhood that the authors find to be significant predictors of outcomes in young adulthood.

${ }^{7}$ In fact, 90 percent of individuals in our sample have at least one contact with the health system per year.

${ }^{8}$ Patients need referrals from their GPs only for consultations with radiologists.
}

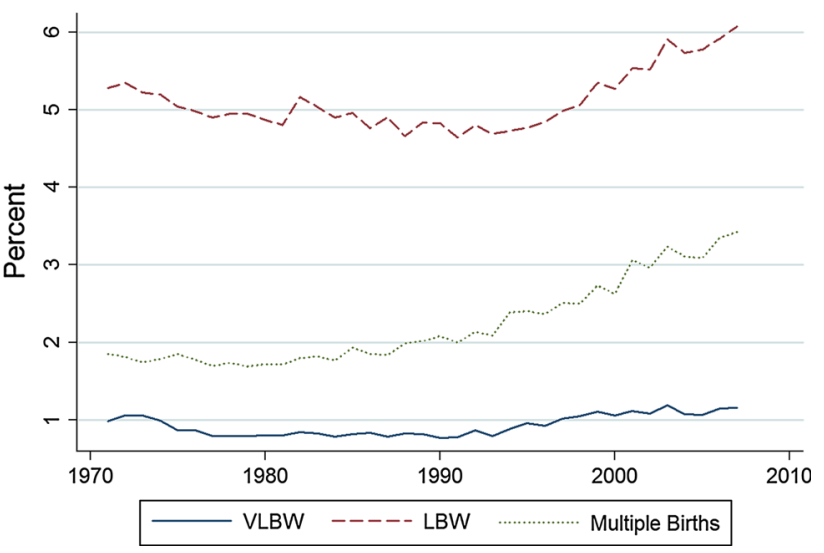

Fig. 1 Shares of VLBW, LBW, and multiple births over time in Austria, 1971-2007

As in many other countries, prenatal care in Austria is expected to identify mothers at risk of delivering LBW babies and to intervene if necessary. Such interventions include medical treatment, nutrition advice, and general lifestyle counseling. ${ }^{9}$ In particular, the Austrian health-care system offers all pregnant women a comprehensive motherchild care program, which was introduced in 1974. This program comprises five basic prenatal health exams for the expectant mother and her unborn baby. ${ }^{10}$ The health checks are undertaken by resident gynecologists who are chosen by the mothers. The pregnant women receive the services free of charge, and the doctors are reimbursed by the sickness funds that pay a predetermined amount for each health examination. Moreover, there is a strong financial incentive for expectant mothers to participate in this program, as eligibility for several family (birth) benefits has been linked to the utilization of basic prenatal medical examinations. As a consequence, Austrian social security register data reveal that more than 95 percent of all mothers participated in all five basic prenatal health checks during the period between 1998 and 2007. Therefore, we conclude that variations in birth weight are unlikely to be caused by differences in prenatal care uptake rates among expectant mothers.

Figure 1 shows that the incidence of LBW in Austria declined until the mid-1990s and started to increase thereafter. This also holds true for the share of VLBW babies. The dotted line in this figure suggests that the increase in the share of LBW babies might be driven by a parallel increase in the percentage of multiple births. This suggestion is supported by the fact that the share of LBW births among singletons has remained constant over time, whereas it has increased for multiple births. The rise in the

\footnotetext{
${ }^{9}$ For the general role of prenatal care, see, e.g., Alexander and Korenbrot [2].

${ }^{10}$ The program also includes five postnatal health examinations of the baby starting at birth up to his or her second year of life.
} 
share of multiple births is, in turn, likely attributable to the increased utilization of assisted reproductive technology, particularly in vitro fertilization (IVF).

\section{Data}

Our empirical analysis uses detailed administrative data from the Upper Austrian Sickness Fund and the Austrian birth register. The Upper Austrian Sickness Fund covers all private employees and their dependents in the province of Upper Austria. The 1.1 million insurants constitute 75 percent of the provincial population. The fund's health records include individual information on doctor visits, medical drug consumption, and the number of days spent hospitalized. We aggregate these data to construct the yearly incidence of hospitalization, expenditures on medical drugs, and medical attendance for each child and young adult from 2005 through 2009. We classify prescribed drugs on the basis of the Anatomical Therapeutic Chemical (ATC) Classification System code, which allows a detailed division of medical drugs according to the organs on which they act. Similarly, by using the ICD-10 (International Statistical Classification of Diseases and Related Health Problems) classification system advocated by the WHO, we classify the number of days spent hospitalized according to the main admission diagnoses. ${ }^{11}$ Both classification systems allow for more detailed insight into the conditions from which LBW children are most likely to suffer.

It must be noted, however, that our consumption data regarding health services might not perfectly reflect the health statuses of individuals. Certain health-care services have a clear preventive character (e.g., postnatal screenings of newborns, routine dental visits, and other check-ups), and health-conscious people are likely to utilize these services more often than less health-conscious people. If a child is born with LBW, a mother may be more concerned about the health of her child and therefore demand preventative health services more frequently. In addition, physicians may also be more risk-averse in such cases and may conduct diagnostic tests more often. Therefore, higher health service utilization may not only indicate the worse health status of LBW children, but also reflect more riskaverse behavior by their mothers and physicians. Even if we cannot unequivocally distinguish the health effect from the risk-aversion effect, the level of detail in our data allows us to determine whether expenditures reflect the utilization of curative (to improve poor health) or preventive (to maintain good health) services. For instance, we

\footnotetext{
11 For further information on these systems, see http://www.whocc. no/atc/structure_and_principles/ and http://www.who.int/classifications/ icd/en/.
}

interpret time spent hospitalized and consumption of medical drugs as better indicators of health status than expenditures on medical attendance at the offices of certain types of ambulatory doctors.

We link individual health service data with the Austrian birth register to obtain information on newborns' birth weights. $^{12}$ The birth register includes information on all births from 1984 to 2007 . Given the structure of our data, we cannot observe health service utilization over a child's complete life cycle. For each individual, utilization data are available for a maximum of 5 consecutive years. Since births to the same mother can be linked, we include sibling fixed effects in our analysis to account for time-invariant unobserved heterogeneity. Consequently, we restrict our data set to siblings. On average, we observe 2.39 siblings per mother and year, and the average age difference between the children is 3.6 years. The resulting unbalanced panel data include information on the yearly outcomes of 113,064 siblings between birth and 21 years of age. Infants enter the sample either in the year of birth or when they join the sickness fund afterward. Children and young adults drop out of the sample if they change their sickness fund within the province of Upper Austria (because of a new employer), move to another province, or die. The majority of children in our sample (72.65 percent) can be observed in each year of the observation period. About 4 percent cannot be observed in each year because they were born after 2005. The remaining children left the sample during the observation period.

Table 1 presents aggregated outcomes by birth weight categories and age groups. The panel for NBW children shows a familiar pattern: both days of hospitalization and outpatient expenditures are highest for the youngest age group (0-1 year old). ${ }^{13}$ Outpatient expenditures and days hospitalized decrease with age with the exception of expenditures on medical drugs; this cost component increases from 25.4 euros per year in the youngest age group to almost 37 euros for those between 15 and 21 years of age. In general, expenditures and days of hospitalization for LBW and VLBW children are higher than those for the NBW group. Particularly striking are the differences in the first years of life. The number of days spent hospitalized among the 0-1-year-old age group varies from 1.2 (NBW) to 6.4 (LBW) to more than 26 days (VLBW). The same pattern holds true for expenditures on medical drugs. Whereas average expenditures on medical drugs among the 0-1-year-old age group of NBW (LBW) babies are 25.4 euros (88.3 euros) per year, this amount is 967 euros for

\footnotetext{
12 The data match is, however, restricted to singletons, as we cannot unambiguously identify the individuals from same-sex multiple births in sickness fund records.

13 This group includes newborns and infants up to 1 year and 11 months old.
} 
Table 1 Means and standard deviations of outcomes by birth weight category and age group

\begin{tabular}{|c|c|c|c|c|}
\hline Age in years & $0-1$ & $2-5$ & $6-14$ & $15-21$ \\
\hline \multicolumn{5}{|c|}{ Normal birth weight $(N B W)$} \\
\hline Days of hospitalization & $\begin{array}{l}1.21 \\
(4.41)\end{array}$ & $\begin{array}{l}0.54 \\
(3.08)\end{array}$ & $\begin{array}{l}0.44 \\
(4.88)\end{array}$ & $\begin{array}{l}0.73 \\
(4.94)\end{array}$ \\
\hline Outpatient expenditures & $\begin{array}{l}227.75 \\
(161.71)\end{array}$ & $\begin{array}{l}198.97 \\
(206.02)\end{array}$ & $\begin{array}{l}194.96 \\
(284.85)\end{array}$ & $\begin{array}{l}184.41 \\
(241.81)\end{array}$ \\
\hline Medical attendance & $\begin{array}{l}202.37 \\
(127.43)\end{array}$ & $\begin{array}{l}167.89 \\
(173.64)\end{array}$ & $\begin{array}{l}162.94 \\
(238.02)\end{array}$ & $\begin{array}{l}147.56 \\
(178.55)\end{array}$ \\
\hline Medical drugs taken & $\begin{array}{l}25.38 \\
(73.60)\end{array}$ & $\begin{array}{l}31.09 \\
(79.17)\end{array}$ & $\begin{array}{l}32.01 \\
(124.51)\end{array}$ & $\begin{array}{l}36.85 \\
(129.92)\end{array}$ \\
\hline Observations & 18,579 & 70,328 & 227,548 & 134,739 \\
\hline \multicolumn{5}{|l|}{ Low birth weight ( $L B W)$} \\
\hline Days of hospitalization & $\begin{array}{l}6.43 \\
(12.07)\end{array}$ & $\begin{array}{l}0.81 \\
(3.82)\end{array}$ & $\begin{array}{l}0.67 \\
(5.94)\end{array}$ & $\begin{array}{l}0.99 \\
(6.17)\end{array}$ \\
\hline Outpatient expenditures & $\begin{array}{l}320.82 \\
(457.60)\end{array}$ & $\begin{array}{l}233.75 \\
(290.41)\end{array}$ & $\begin{array}{l}219.19 \\
(327.72)\end{array}$ & $\begin{array}{l}202.38 \\
(292.17)\end{array}$ \\
\hline Medical attendance & $\begin{array}{l}232.56 \\
(188.59)\end{array}$ & $\begin{array}{l}191.98 \\
(239.20)\end{array}$ & $\begin{array}{l}180.64 \\
(280.07)\end{array}$ & $\begin{array}{l}158.86 \\
(196.71)\end{array}$ \\
\hline Medical drugs taken & $\begin{array}{l}88.25 \\
(392.48)\end{array}$ & $\begin{array}{l}41.77 \\
(136.65)\end{array}$ & $\begin{array}{l}38.55 \\
(134.40)\end{array}$ & $\begin{array}{l}43.52 \\
(182.33)\end{array}$ \\
\hline Observations & 854 & 2,957 & 7,926 & 4,856 \\
\hline \multicolumn{5}{|c|}{ Very low birth weight (VLBW) } \\
\hline Days of hospitalization & $\begin{array}{l}26.19 \\
(35.80)\end{array}$ & $\begin{array}{l}1.21 \\
(4.06)\end{array}$ & $\begin{array}{l}0.72 \\
(3.43)\end{array}$ & $\begin{array}{l}1.19 \\
(5.87)\end{array}$ \\
\hline Outpatient expenditures & $\begin{array}{l}1173.76 \\
(1263.94)\end{array}$ & $\begin{array}{l}289.123 \\
(485.01)\end{array}$ & $\begin{array}{l}319.83 \\
(506.29)\end{array}$ & $\begin{array}{l}218.17 \\
(369.03)\end{array}$ \\
\hline Medical attendance & $\begin{array}{l}207.03 \\
(175.48)\end{array}$ & $\begin{array}{l}208.39 \\
(333.41)\end{array}$ & $\begin{array}{l}256.07 \\
(430.15)\end{array}$ & $\begin{array}{l}176.83 \\
(274.54)\end{array}$ \\
\hline Medical drugs taken & $\begin{array}{l}966.73 \\
(1225.01)\end{array}$ & $\begin{array}{l}80.73 \\
(289.65)\end{array}$ & $\begin{array}{l}63.75 \\
(223.12)\end{array}$ & $\begin{array}{l}41.34 \\
(173.87)\end{array}$ \\
\hline Observations & 119 & 462 & 1,136 & 425 \\
\hline
\end{tabular}

This table provides the annual means and standard deviations (in parentheses) of outcome variables by birth weight category and age group. The figures represent an unbalanced panel data set that covers the period from 2005 through 2009. Outpatient expenditures and expenditures on medical attendance and medical drugs are measured in 2009 euros per year. Note that insurants contribute to up to five observations and may be represented in up to three age groups

their VLBW counterparts. The general impression made by Table 1 is that differences in outcomes between birth weight categories decrease with increasing age; however, some differences persist until young adulthood, as can be seen from the figures for the 15-21-year-old age group.

\section{Methods}

To identify the impacts of VLBW and LBW on health throughout the early life cycle, we estimate the subsequent equation for the following age groups: infancy and early childhood (age groups $0-1$ and 2-5 years, respectively), compulsory schooling (age group 6-14 years), and adolescence and early adulthood (age group 15-21 years):

$$
\begin{gathered}
y_{i j t}=\alpha+\beta_{1} \mathrm{vlbw}_{i j}+\beta_{2} \mathrm{lbw}_{i j}+\beta_{3} X_{i j t}+ \\
\beta_{4} \mathrm{age}_{i j}+\mu_{j}+\lambda_{t}+v_{i j t}
\end{gathered}
$$

where $y_{i j t}$ denotes the outcome of child $i$ with mother $j$ at time $t$. The dummy variables $\mathrm{vlbw}_{i j}$ and $\mathrm{lbw}_{i j}$ indicate whether a baby was born with VLBW (below 1,500 g) or with LBW (between 1,500 and 2,500 g), respectively. $X_{i j t}$ is a vector of child controls, including the age and sex of the child, number of siblings, and birth order of the child. ${ }^{14}$ Moreover, we include the mother's age at birth, age ${ }_{i j}$; sibling fixed-effects $\mu_{j}$, to control for time-invariant; unobserved family characteristics and period dummies, $\lambda_{t}$. Finally, $v_{i j t}$ denotes the error term.

LBW can originate from two sources: (1) intrauterine growth restriction (IUGR) and (2) prematurity. In the first case, a fetus does not grow at the normal rate and is more likely to be small for its gestational age. If there are two newborns from a multiple birth, and one is affected by IUGR, then the affected infant is more likely to have LBW, even though both spent the same time in utero. Differences in birth weight are therefore solely caused by intrauterine growth rates. In contrast, prematurity indicates a baby that has LBW because she was born too early and not because of retarded growth. This distinction has important implications for the analysis of twin pairs. Twin studies restrict the source of variation in birth weight to intrauterine growth restriction, since by definition twins spend the same amount of time in utero. Kramer [22], however, states that LBW in developed countries is mainly determined by prematurity. We have recognized that the siblings approach cannot control for the full spectrum of unobserved heterogeneity, such as twin fixed effects. However, if one controls for twin fixed effects, the source of variation is restricted to IUGR since gestational duration is the same for a twin pair. The inclusion of twin fixed effects might therefore underestimate the effects of LBW in developed countries. ${ }^{15}$ It is important to note that sibling fixed effects might control for gestational age if it is identical between siblings. In fact, our data show that the variation in gestational duration for one mother over the course of different births is moderate. The duration of gestation differs by 1 week or less for 68.5 percent of siblings in our data set. Although it is desirable from an econometric

\footnotetext{
14 Birth weight increases with the number of deliveries, and a mother may change her behavior with subsequent children if she becomes more experienced.

15 However, a smaller effect of LBW in twin fixed effects estimations can also be caused by omitted variables for which we do not control in our specification, including sibling fixed effects.
} 
Table 2 Main outcomes (FE)

\begin{tabular}{|c|c|c|c|c|c|c|c|c|}
\hline \multirow[b]{2}{*}{ Age in years } & \multicolumn{4}{|c|}{ Very low birth weight (VLBW) } & \multicolumn{4}{|c|}{ Low birth weight (LBW) } \\
\hline & $0-1$ & $2-5$ & $6-14$ & $15-21$ & $0-1$ & $2-5$ & $6-14$ & $15-21$ \\
\hline Days of hospitalization & $\begin{array}{l}14.92^{* * * *} \\
(4.89)\end{array}$ & $\begin{array}{l}0.58 * * \\
(0.26)\end{array}$ & $\begin{array}{l}0.25^{*} \\
(0.14)\end{array}$ & $\begin{array}{l}-0.12 \\
(1.00)\end{array}$ & $\begin{array}{l}4.30 * * * \\
(1.30)\end{array}$ & $\begin{array}{l}0.20 * \\
(0.11)\end{array}$ & $\begin{array}{l}0.17 * * * \\
(0.06)\end{array}$ & $\begin{array}{l}0.36 * \\
(0.21)\end{array}$ \\
\hline NBW mean & 1.21 & 0.54 & 0.44 & 0.73 & 1.21 & 0.54 & 0.44 & 0.73 \\
\hline Outpatient expenditures & $\begin{array}{l}412.39 * * \\
(185.05)\end{array}$ & $\begin{array}{l}72.13 * \\
(37.79)\end{array}$ & $\begin{array}{l}131.16 \text { *** } \\
(37.49)\end{array}$ & $\begin{array}{l}-10.60 \\
(49.85)\end{array}$ & $\begin{array}{l}129.41 * * * \\
(46.03)\end{array}$ & $\begin{array}{l}41.73 * * * \\
(11.94)\end{array}$ & $\begin{array}{l}15.62 * \\
(8.22)\end{array}$ & $\begin{array}{l}14.49 \\
(9.18)\end{array}$ \\
\hline NBW mean & 227.75 & 198.98 & 194.95 & 184.41 & 227.75 & 198.98 & 194.95 & 184.41 \\
\hline Medical attendance & $\begin{array}{l}79.23 \\
(63.26)\end{array}$ & $\begin{array}{l}48.74 \\
(32.12)\end{array}$ & $\begin{array}{l}94.57 * * * \\
(33.48)\end{array}$ & $\begin{array}{l}-9.02 \\
(42.01)\end{array}$ & $\begin{array}{l}20.51 * * \\
(9.31)\end{array}$ & $\begin{array}{l}28.44 * * * \\
(9.88)\end{array}$ & $\begin{array}{l}13.47 * * \\
(6.80)\end{array}$ & $\begin{array}{l}4.16 \\
(5.65)\end{array}$ \\
\hline NBW mean & 202.37 & 167.89 & 162.94 & 147.56 & 202.37 & 167.89 & 162.94 & 147.56 \\
\hline Medical drugs taken & $\begin{array}{l}333.17 * \\
(177.51)\end{array}$ & $\begin{array}{l}23.39 * * \\
(11.29)\end{array}$ & $\begin{array}{l}36.59 * * * \\
(14.33)\end{array}$ & $\begin{array}{l}-1.59 \\
(18.88)\end{array}$ & $\begin{array}{l}108.89 * * \\
(44.90)\end{array}$ & $\begin{array}{l}13.30 * * \\
(5.92)\end{array}$ & $\begin{array}{l}2.15 \\
(4.04)\end{array}$ & $\begin{array}{l}10.33^{*} \\
(6.22)\end{array}$ \\
\hline NBW mean & 25.38 & 31.09 & 32.01 & 36.85 & 25.38 & 31.09 & 32.01 & 36.85 \\
\hline
\end{tabular}

This table summarizes sibling fixed-effects (FE) estimation results for the effects of VLBW and LBW on four different health outcomes for different age groups. Each entry reflects a separate estimation. Outpatient expenditures and expenditures on medical attendance and medical drugs are measured in 2009 euros per year. Standard errors (in parentheses) are robust to clustering at the individual level and to heteroskedasticity of unknown form. *,**, and $* * *$ indicate statistical significance at the 10,5 , and 1 percent levels, respectively. The estimations also control for the ages of the child and mother, the sex of the child, the number of siblings, birth order, and year fixed effects

perspective to control for all mother-specific factors ${ }^{16}$, twin analysis is not without caveats. For example, Almond et al. [5] observe that within-twin variations in birth weight are large in their pooled sample of twins, although they concede that the identities and relative contributions of the environmental factors that cause intrapair variation and their modifiability are unknown. Moreover, it remains somewhat unclear whether within-twin variation may predict the impacts of caloric intake on health outcomes in single births. Black et al. [10] argue that there are substantial differences between single and twin births, the most remarkable difference being that twins fall disproportionally into the lower part of the birth weight distribution. However, they argue that, conditionally depending on birth weight, the outcomes (mortality, height, IQ, earnings) of singletons and twins are similar, and their results may be generalizable to the rest of the population. Moreover, the authors show that sibling fixed effects estimates of later outcomes are quite similar to twin fixed effects estimates. As compared to twin analyses, we would therefore not expect substantial differences in results based on our identification strategy, which controls for timeinvariant mother heterogeneity (sibling fixed effects). ${ }^{17}$

\footnotetext{
16 To make sure to control for all unobserved heterogeneity (including genetic endowment), the analysis needs to be restricted to monozygotic twins only.

17 Finally, twin (and sibling) fixed effects may be biased if parents invest differently in each sibling. If parents favor the disadvantaged child, sibling fixed effects understate the true effects of birth weight. However, the effects tend to be overstated if parents invest more in the stronger child.
}

\section{Empirical results}

This section includes our estimation results. First, we present fixed-effects results for the main outcomes (days spent hospitalized, outpatient expenditures on medical drugs, and medical attendance) in Table 2. The table includes results for children born with VLBW and LBW. We also estimate these regressions without fixed effects. ${ }^{18}$ A comparison between these and the fixed effects results reveals that the OLS estimates are generally upward biased and that this bias decreases with age. We begin the presentation of results with the analysis of effects during infancy and early childhood.

Infancy and early childhood

As shown in Table 2, VLBW infants spend 14.9 more days hospitalized $(1,231 \text { percent })^{19}$ in their first year of life than do their NBW counterparts, suggesting that newborns weighing below $1,500 \mathrm{~g}$ require significantly more inpatient care immediately after birth. ${ }^{20}$ For LBW infants, their 4.3 days of hospitalization is still 355 percent higher than the number of days spent hospitalized by the NBW reference group. In order to analyze the determinants of

\footnotetext{
18 These results are presented in Table A.1 of the web appendix.

${ }_{19}$ Percentages are calculated with reference to the means among NBW infants throughout the text.

${ }^{20}$ Note that our sample only includes infants who survived the first month of life. An additional selection process may take place when a fetus dies during pregnancy and is not born with LBW. Therefore, the estimates are likely to represent the lower bounds of the effects.
} 
inpatient stays in more detail, we split hospitalization time according to the ICD-10 classification. This decomposition, presented in Table 3, shows that for VLBW newborns in their first year of life, an average of 10.4 out of the total 14.9 days spent hospitalized can be explained by "certain conditions originating in the perinatal period." This diagnosis code includes, among other maladies, the symptoms of short gestational duration, respiratory distress, low birth weight for a given gestational age, and extreme immaturity. The most common medical services provided for these newborns include noninvasive, intensive monitoring; general intensive care; respiratory therapy; continuous monitoring of fluid balance; and partial parenteral nutrition. In contrast, for LBW infants, only one third of total inpatient time ( 1.3 out of 4.3 days of hospitalization) is attributable to "certain conditions originating in the perinatal period," but almost 40 percent of inpatient time is caused by diseases of the respiratory system. Another significant effect observed regarding hospitalization is that VLBW infants have a higher risk than others to contract diseases of the nervous system in their first year of life. In particular, VLBW newborns suffer more often from epilepsy and sleep apnea. These diagnoses contribute to 0.42 days spent hospitalized, during which the young patients mainly receive magnetic resonance tomography (under anesthesia) and general intensive care.

Although the hospitalization time for infants in early childhood (age group 2-5 years) strongly declines, significant between-group differences remain. VLBW infants still spend more than twice as many days hospitalized as NBW infants. In particular, we find that VLBW infants are more likely to suffer in early childhood from diseases of the respiratory system (335 percent), certain infectious and parasitic diseases (41 percent), and diseases of the nervous system (1,018 percent). A moderate increase in hospitalization time due to diseases of the nervous system and the digestive system was also found for LBW infants in early childhood. However, because of the correlation between birth weight and mortality, particularly early in life, the decline of LBW coefficients from infancy to early childhood may be (at least to some extent) explained by sample selection. Therefore, the decrease in coefficients from infancy to early childhood does not necessarily reflect improved health among VLBW (LBW) newborns, but may also indicate the selection of healthier infants since those with the worst health die. Following this argument, we ran a sensitivity check by restricting our sample to those individuals who survived the youngest age category and were therefore observed in early childhood. The sensitivity check shows that the effects on hospitalization time decrease by 3 days for VLBW infants and 0.2 days for LBW infants in their first year of life. This indicates that the effects are not mainly driven by selection.
Cost-increasing effects also occur in the outpatient sector. As shown in Table 2, health expenditures on VLBW (LBW) babies in their first year of life are 412.39 (129.41) euros higher than those on their NBW counterparts. These figures represent elevations of 181 percent (57 percent). More than 80 percent of these effects are attributed to an increase in the consumption of medical drugs. The disaggregated analysis of drug intake in Table $5^{21}$ shows that these effects are mainly driven by anti-infectives, which contribute about 90 percent of the aggregate between-group effects on medical drug consumption. VLBW (LBW) newborns require 308.29 (98.50) euros more in anti-infectives in their first year of life than do NBW babies. We also find significantly elevated expenditures on residual drugs among VLBW infants. ${ }^{22}$ In early childhood, expenditures on anti-infectives are still higher among VLBW newborns; however, the effect is substantially smaller than that observed during the first year of life. Further cost-increasing effects among both lower-birthweight groups on drugs affecting the alimentary tract and metabolism indicate that the lower-birth-weight groups have increased rates of metabolic disorders in early childhood.

Significant aggregate effects on medical attendance during infancy can only be discerned for LBW babies, whose expenditures on visits to resident doctors are 20.51 euros (10 percent) higher than those for NBW children. This effect is maintained during LBW babies' early childhoods. Whereas LBW infants utilize the services of resident doctors more often, VLBW babies mainly receive inpatient services throughout their early lives. The disaggregated analysis shows that the parents of LBW infants consult GPs more often in the first year of their infants' lives, whereas the significant effect among the 2-5-year age group is mainly driven by expenditures at disabled centers and on pediatric services. The significant impact of birth weight on the utilization of disabled centers may indicate that children born at LBW are at a higher risk of suffering from severe physical or psychic impairments. Finally, LBW children receive more diagnostic services (radiological and laboratory examinations) during early childhood than do NBW children.

Although we do not identify an aggregate effect on expenditures on doctor visits among VLBW infants between 2-5 years of age, this group of infants spends 12.99 euros (22 percent) more on the services of pediatricians than do

\footnotetext{
${ }^{21}$ For a limited number of drugs, the data do not contain information on the ATC codes. These drugs are included in the residual category.

${ }^{22}$ The counterintuitive decrease in expenditures on musculoskeletal drugs is quantitatively small.
} 
Table 3 Days of hospitalization by diagnosis (FE)

\begin{tabular}{|c|c|c|c|c|c|c|c|c|}
\hline \multirow[b]{2}{*}{ Age in years } & \multicolumn{4}{|c|}{ Very low birth weight (VLBW) } & \multicolumn{4}{|c|}{ Low birth weight (LBW) } \\
\hline & $0-1$ & $2-5$ & $6-14$ & $15-21$ & $0-1$ & $2-5$ & $6-14$ & $15-21$ \\
\hline Certain infectious and parasitic diseases & $\begin{array}{l}1.05 \\
(0.94)\end{array}$ & $\begin{array}{l}0.22 * * \\
(0.09)\end{array}$ & $\begin{array}{l}0.06 \\
(0.04)\end{array}$ & $\begin{array}{l}-0.01 \\
(0.01)\end{array}$ & $\begin{array}{l}0.13 \\
(0.17)\end{array}$ & $\begin{array}{l}-0.01 \\
(0.03)\end{array}$ & $\begin{array}{l}0.01 \\
(0.01)\end{array}$ & $\begin{array}{l}-0.03 \\
(0.03)\end{array}$ \\
\hline NBW mean & 0.12 & 0.06 & 0.02 & 0.02 & 0.12 & 0.06 & 0.02 & 0.02 \\
\hline Neoplasms & $\begin{array}{l}0.00 \\
(0.00)\end{array}$ & $\begin{array}{l}0.00 \\
(0.01)\end{array}$ & $\begin{array}{l}-0.31 \\
(0.28)\end{array}$ & $\begin{array}{l}0.04 \\
(0.05)\end{array}$ & $\begin{array}{l}0.00 \\
(0.00)\end{array}$ & $\begin{array}{l}0.01 \\
(0.01)\end{array}$ & $\begin{array}{l}-0.02^{*} \\
(0.01)\end{array}$ & $\begin{array}{l}-0.00 \\
(0.00)\end{array}$ \\
\hline NBW mean & 0.01 & 0.01 & 0.01 & 0.01 & 0.01 & 0.01 & 0.01 & 0.01 \\
\hline Mental and behavioral disorders & $\begin{array}{l}-0.00 \\
(0.00)\end{array}$ & $\begin{array}{l}-0.07 \\
(0.08)\end{array}$ & $\begin{array}{l}0.11 \\
(0.08)\end{array}$ & $\begin{array}{l}-0.79 \\
(1.29)\end{array}$ & $\begin{array}{l}0.00 \\
(0.00)\end{array}$ & $\begin{array}{l}0.03 \\
(0.03)\end{array}$ & $\begin{array}{l}0.16^{\text {** }} \\
(0.08)\end{array}$ & $\begin{array}{l}0.68 \\
(0.42)\end{array}$ \\
\hline NBW mean & 0.00 & 0.03 & 0.11 & 0.17 & 0.00 & 0.03 & 0.11 & 0.17 \\
\hline Diseases of the nervous system & $\begin{array}{l}0.42 * * \\
(0.21)\end{array}$ & $\begin{array}{l}0.18 * * \\
(0.09)\end{array}$ & $\begin{array}{l}0.30 * * \\
(0.13)\end{array}$ & $\begin{array}{l}0.46 \\
(0.33)\end{array}$ & $\begin{array}{l}0.05 \\
(0.13)\end{array}$ & $\begin{array}{l}0.07 * * \\
(0.03)\end{array}$ & $\begin{array}{l}0.07 * * \\
(0.03)\end{array}$ & $\begin{array}{l}0.10 \\
(0.08)\end{array}$ \\
\hline NBW mean & 0.02 & 0.02 & 0.02 & 0.02 & 0.02 & 0.02 & 0.02 & 0.02 \\
\hline Diseases of the eye and adnexa & $\begin{array}{l}-0.27 \\
(0.51)\end{array}$ & $\begin{array}{l}-0.11^{* *} \\
(0.05)\end{array}$ & $\begin{array}{l}-0.05 \\
(0.07)\end{array}$ & $\begin{array}{l}0.08 \\
(0.08)\end{array}$ & $\begin{array}{l}0.31 \\
(0.31)\end{array}$ & $\begin{array}{l}-0.03 \\
(0.04)\end{array}$ & $\begin{array}{l}0.03 * * * \\
(0.01)\end{array}$ & $\begin{array}{l}0.04 \\
(0.05)\end{array}$ \\
\hline NBW mean & 0.03 & 0.03 & 0.01 & 0.02 & 0.03 & 0.03 & 0.01 & 0.02 \\
\hline Diseases of the respiratory system & $\begin{array}{l}1.17 \\
(0.83)\end{array}$ & $\begin{array}{l}0.54 * \\
(0.29)\end{array}$ & $\begin{array}{l}0.00 \\
(0.05)\end{array}$ & $\begin{array}{l}-0.02 \\
(0.05)\end{array}$ & $\begin{array}{l}1.57 * * \\
(0.72)\end{array}$ & $\begin{array}{l}0.23 \\
(0.15)\end{array}$ & $\begin{array}{l}0.01 \\
(0.01)\end{array}$ & $\begin{array}{l}0.07 * \\
(0.04)\end{array}$ \\
\hline NBW mean & 0.27 & 0.16 & 0.05 & 0.05 & 0.27 & 0.16 & 0.05 & 0.05 \\
\hline Diseases of the digestive system & $\begin{array}{l}-0.31 \\
(0.74)\end{array}$ & $\begin{array}{l}0.05 \\
(0.04)\end{array}$ & $\begin{array}{l}0.03 \\
(0.03)\end{array}$ & $\begin{array}{l}0.12 \\
(0.11)\end{array}$ & $\begin{array}{l}0.04 \\
(0.12)\end{array}$ & $\begin{array}{l}0.02 * \\
(0.01)\end{array}$ & $\begin{array}{l}-0.02 \\
(0.02)\end{array}$ & $\begin{array}{l}-0.00 \\
(0.03)\end{array}$ \\
\hline NBW mean & 0.05 & 0.04 & 0.05 & 0.07 & 0.05 & 0.04 & 0.05 & 0.07 \\
\hline Diseases of the genitourinary system & $\begin{array}{l}-0.48 \\
(0.45)\end{array}$ & $\begin{array}{l}-0.04 \\
(0.04)\end{array}$ & $\begin{array}{l}0.01 \\
(0.02)\end{array}$ & $\begin{array}{l}-0.17 * * \\
(0.07)\end{array}$ & $\begin{array}{l}-0.02 \\
(0.11)\end{array}$ & $\begin{array}{l}-0.03 \\
(0.02)\end{array}$ & $\begin{array}{l}-0.00 \\
(0.01)\end{array}$ & $\begin{array}{l}-0.01 \\
(0.03)\end{array}$ \\
\hline NBW mean & 0.06 & 0.03 & 0.02 & 0.03 & 0.06 & 0.03 & 0.02 & 0.03 \\
\hline Certain conditions originating in the perinatal period & $\begin{array}{l}10.37 * * \\
(4.41)\end{array}$ & $\begin{array}{l}0.02 \\
(0.02)\end{array}$ & $\begin{array}{l}0.00 \\
(0.00)\end{array}$ & $\begin{array}{l}0.00 \\
(0.00)\end{array}$ & $\begin{array}{l}1.32 * \\
(0.77)\end{array}$ & $\begin{array}{l}-0.01 \\
(0.01)\end{array}$ & $\begin{array}{l}-0.00 \\
(0.00)\end{array}$ & $\begin{array}{l}0.00 \\
(0.00)\end{array}$ \\
\hline NBW mean & 0.24 & 0.00 & 0.00 & 0.00 & 0.24 & 0.00 & 0.00 & 0.00 \\
\hline $\begin{array}{l}\text { Injury, poisoning and certain other consequences of external } \\
\text { causes }\end{array}$ & $\begin{array}{l}0.11 \\
(0.12)\end{array}$ & $\begin{array}{l}0.06 \\
(0.07)\end{array}$ & $\begin{array}{l}-0.01 \\
(0.02)\end{array}$ & $\begin{array}{l}-0.05 \\
(0.04)\end{array}$ & $\begin{array}{l}0.12 \\
(0.12)\end{array}$ & $\begin{array}{l}0.01 \\
(0.02)\end{array}$ & $\begin{array}{l}-0.02 * \\
(0.01)\end{array}$ & $\begin{array}{l}-0.06 \\
(0.16)\end{array}$ \\
\hline NBW mean & 0.07 & 0.05 & 0.04 & 0.12 & 0.07 & 0.05 & 0.04 & 0.12 \\
\hline
\end{tabular}

This table summarizes sibling fixed-effects (FE) estimation results for the effect of VLBW and LBW on days of hospitalization according to admission diagnoses (ICD-10 classification) for different age groups. Each entry reflects a separate estimation. Standard errors (in parentheses) are robust to clustering at the individual level and to heteroskedasticity of unknown form. *,**, and *** indicate statistical significance at the 10 , 5 , and 1 percent level, respectively. The estimations also control for the age of the child and the mother, the sex of the child, the number of siblings, birth order, and year fixed effects

NBW infants during early childhood (see Table 4). We interpret this as evidence that pediatrician services of resident doctors substitute for step-by-step inpatient treatment as newborns age. An alternative explanation is that parents of VLBW infants see their pediatricians more often for regular health check-ups than do parents of NBW children.

\section{Compulsory schooling}

The most striking result of our analysis of children born with LBW and VLBW during the age of compulsory schooling is the shift of health problems toward mental illness and difficulties with concentration. For both 
Table 4 Medical attendance by provider category (FE)

\begin{tabular}{|c|c|c|c|c|c|c|c|c|}
\hline \multirow[b]{2}{*}{ Age in years } & \multicolumn{4}{|c|}{ Very low birth weight (VLBW) } & \multicolumn{4}{|c|}{ Low birth weight (LBW) } \\
\hline & $0-1$ & $2-5$ & $6-14$ & $15-21$ & $0-1$ & $2-5$ & $6-14$ & $15-21$ \\
\hline \multirow[t]{2}{*}{ GP } & 6.61 & -5.59 & 2.12 & -11.12 & $8.60 *$ & 1.30 & 0.31 & 0.07 \\
\hline & $(7.91)$ & $(4.31)$ & $(2.27)$ & (7.18) & $(4.75)$ & $(1.58)$ & $(0.84)$ & $(1.51)$ \\
\hline NBW mean & 66.80 & 59.02 & 37.56 & 47.50 & 66.80 & 59.02 & 37.56 & 47.50 \\
\hline \multirow[t]{2}{*}{ Pediatrician } & -0.37 & $12.99 * * *$ & 2.72 & 0.37 & 9.20 & $4.16^{* *}$ & -0.15 & 0.58 \\
\hline & (20.26) & $(5.03)$ & $(1.72)$ & $(0.34)$ & (7.94) & $(1.77)$ & $(0.60)$ & $(0.37)$ \\
\hline NBW mean & 118.12 & 50.23 & 9.63 & 1.15 & 118.12 & 50.23 & 9.63 & 1.15 \\
\hline \multirow[t]{2}{*}{ Pulmonologist } & 0.13 & 1.08 & $2.32 *$ & -0.93 & 0.19 & -0.01 & -0.25 & -0.21 \\
\hline & $(0.17)$ & $(1.04)$ & $(1.26)$ & $(1.36)$ & $(0.16)$ & $(0.45)$ & $(0.43)$ & $(0.52)$ \\
\hline NBW mean & 0.28 & 1.48 & 2.81 & 2.83 & 0.28 & 1.48 & 2.81 & 2.83 \\
\hline \multirow[t]{2}{*}{ Psychiatrist } & -0.00 & 0.91 & 1.29 & -0.13 & -0.01 & -0.38 & 0.20 & $1.93 * *$ \\
\hline & $(0.01)$ & $(0.89)$ & $(1.21)$ & $(1.29)$ & $(0.01)$ & $(0.37)$ & $(0.47)$ & $(0.92)$ \\
\hline NBW mean & 0.04 & 0.51 & 1.98 & 2.98 & 0.04 & 0.51 & 1.98 & 2.98 \\
\hline \multirow[t]{2}{*}{ Speech therapist } & 0.04 & 1.70 & 2.65 & -0.45 & 0.03 & 4.18 & $4.16^{*}$ & $-0.41 *$ \\
\hline & $(0.06)$ & (7.79) & $(3.81)$ & $(0.38)$ & $(0.04)$ & $(4.32)$ & $(2.24)$ & $(0.25)$ \\
\hline NBW mean & 0.11 & 11.51 & 7.46 & 0.38 & 0.11 & 11.51 & 7.46 & 0.38 \\
\hline \multirow[t]{2}{*}{ Disabled center } & 23.27 & 21.10 & $37.45^{*}$ & 22.14 & 2.56 & $11.61 * *$ & $6.54 *$ & $4.81 * * *$ \\
\hline & $(21.91)$ & (15.57) & $(21.89)$ & $(14.79)$ & $(2.52)$ & $(4.71)$ & $(3.49)$ & $(1.85)$ \\
\hline NBW mean & 0.60 & 3.68 & 4.00 & 0.71 & 0.60 & 3.68 & 4.00 & 0.71 \\
\hline \multirow[t]{2}{*}{ Therapy $^{\mathrm{a}}$} & 54.56 & 16.57 & $31.82 * *$ & 22.71 & 0.30 & 5.46 & 3.79 & 2.33 \\
\hline & $(45.29)$ & (11.66) & (12.67) & $(14.86)$ & $(4.40)$ & $(3.42)$ & $(2.60)$ & $(1.61)$ \\
\hline NBW mean & 6.85 & 4.82 & 6.07 & 4.80 & 6.85 & 4.82 & 6.07 & 4.80 \\
\hline \multirow[t]{2}{*}{ Diagnostics } & -2.38 & 0.07 & 0.23 & -4.77 & -0.47 & $1.42 * * *$ & -0.62 & -0.07 \\
\hline & $(2.39)$ & $(1.39)$ & $(0.99)$ & $(3.18)$ & $(2.61)$ & $(0.53)$ & $(0.42)$ & $(0.95)$ \\
\hline NBW mean & 3.39 & 3.05 & 4.74 & 10.51 & 3.39 & 3.05 & 4.74 & 10.51 \\
\hline Residual & -6.11 & -0.87 & 13.39 & -37.63 & 0.06 & 0.45 & -0.65 & -4.97 \\
\hline category & $(5.62)$ & $(6.62)$ & $(9.86)$ & (28.16) & $(1.94)$ & $(2.04)$ & $(3.73)$ & $(3.54)$ \\
\hline NBW mean & 5.66 & 33.26 & 88.28 & 76.22 & 5.66 & 33.26 & 88.28 & 76.22 \\
\hline
\end{tabular}

This table summarizes sibling fixed-effects (FE) estimation results for the effects of VLBW and LBW on expenditures on subcategories of medical attendance. Each entry reflects a separate estimation. Expenditures are measured in 2009 euros per year. Standard errors (in parentheses) are robust to clustering at the individual level and to heteroskedasticity of unknown form. $*$, ** and *** indicate statistical significance at the 10 , 5 , and 1 percent levels, respectively. The estimations also control for the ages of the child and mother, the sex of the child, the number of siblings, birth order, and year fixed effects

a Orthopedic services, physiotherapy, and hippotherapy

lower-birth-weight groups, we still find that hospitalization is significantly increased in this age category. VLBW and LBW newborns spend 56 and 39 percent more days hospitalized, respectively, than do their NBW counterparts in the same age group. The increase in the number of days spent hospitalized among VLBW children is solely driven by diseases of the nervous system. These patients are particularly likely to suffer from epilepsy (or epileptic syndrome), facial palsy, and several forms of migraine and tension headaches. The most frequent treatments they receive are magnetic resonance tomography, intensive epilepsy monitoring, physiotherapy, and logopedic and phoniatric therapy. Mental and behavioral disorders are quantitatively even more important for the LBW group. Days of hospitalization due to adjustment disorders, hospitalism, attention deficit disorders, hyperactivity syndrome, or other syndromes of social behavior are 140 percent higher than those for NBW school-age children. Consequently, these children receive significantly more day clinic treatment in psychiatry, ergo- and 
Table 5 Medical drugs taken by category (FE)

\begin{tabular}{|c|c|c|c|c|c|c|c|c|}
\hline \multirow[b]{2}{*}{ Age in years } & \multicolumn{4}{|c|}{ Very low birth weight (VLBW) } & \multicolumn{4}{|c|}{ Low birth weight (LBW) } \\
\hline & $0-1$ & $2-5$ & $6-14$ & $15-21$ & $0-1$ & $2-5$ & $6-14$ & $15-21$ \\
\hline Alimentary tract and metabolism & $\begin{array}{l}2.49 \\
(2.82)\end{array}$ & $\begin{array}{l}3.18^{*} \\
(1.81)\end{array}$ & $\begin{array}{l}0.11 \\
(0.38)\end{array}$ & $\begin{array}{l}0.33 \\
(0.45)\end{array}$ & $\begin{array}{l}-0.47 \\
(0.82)\end{array}$ & $\begin{array}{l}1.08^{* *} \\
(0.51)\end{array}$ & $\begin{array}{l}0.40 \\
(1.34)\end{array}$ & $\begin{array}{l}2.82 * \\
(1.66)\end{array}$ \\
\hline NBW mean & 2.62 & 1.90 & 1.73 & 3.52 & 2.62 & 1.90 & 1.73 & 3.52 \\
\hline Genitourinary system & $\begin{array}{l}-0.03 \\
(0.08)\end{array}$ & $\begin{array}{l}0.20 \\
(0.37)\end{array}$ & $\begin{array}{l}0.25 \\
(0.78)\end{array}$ & $\begin{array}{l}-0.46^{*} \\
(0.23)\end{array}$ & $\begin{array}{l}0.01 \\
(0.08)\end{array}$ & $\begin{array}{l}0.04 \\
(0.05)\end{array}$ & $\begin{array}{l}0.40 * \\
(0.22)\end{array}$ & $\begin{array}{l}0.02 \\
(0.08)\end{array}$ \\
\hline NBW mean & 0.08 & 0.15 & 0.20 & 0.48 & 0.08 & 0.15 & 0.20 & 0.48 \\
\hline Anti-infectives for systemic use & $\begin{array}{l}308.29 * \\
(175.94)\end{array}$ & $\begin{array}{l}14.82 * \\
(7.65)\end{array}$ & $\begin{array}{l}1.72 * \\
(1.02)\end{array}$ & $\begin{array}{l}-3.03 * * \\
(1.34)\end{array}$ & $\begin{array}{l}98.50 * * \\
(43.63)\end{array}$ & $\begin{array}{l}7.46 \\
(5.22)\end{array}$ & $\begin{array}{l}0.13 \\
(0.34)\end{array}$ & $\begin{array}{l}0.41 \\
(0.63)\end{array}$ \\
\hline NBW mean & 8.30 & 12.10 & 7.50 & 8.34 & 8.30 & 12.10 & 7.50 & 8.34 \\
\hline Musculoskeletal system & $\begin{array}{l}-0.35^{*} \\
(0.20)\end{array}$ & $\begin{array}{l}-0.20 \\
(0.13)\end{array}$ & $\begin{array}{l}0.27 \\
(0.28)\end{array}$ & $\begin{array}{l}-0.35 \\
(0.33)\end{array}$ & $\begin{array}{l}-0.14 * \\
(0.08)\end{array}$ & $\begin{array}{l}0.04 \\
(0.09)\end{array}$ & $\begin{array}{l}0.07 \\
(0.07)\end{array}$ & $\begin{array}{l}0.49 \\
(0.60)\end{array}$ \\
\hline NBW mean & 0.20 & 0.47 & 0.74 & 1.41 & 0.20 & 0.47 & 0.74 & 1.41 \\
\hline Nervous system & $\begin{array}{l}2.39 \\
(2.32)\end{array}$ & $\begin{array}{l}7.56 \\
(5.73)\end{array}$ & $\begin{array}{l}11.16^{* * *} \\
(5.39)\end{array}$ & $\begin{array}{l}24.52 \\
(15.41)\end{array}$ & $\begin{array}{l}2.86 \\
(3.07)\end{array}$ & $\begin{array}{l}0.73 \\
(0.47)\end{array}$ & $\begin{array}{l}1.74 \\
(1.65)\end{array}$ & $\begin{array}{l}5.57 \\
(3.74)\end{array}$ \\
\hline NBW mean & 0.44 & 0.67 & 3.32 & 5.09 & 0.44 & 0.67 & 3.32 & 5.09 \\
\hline Respiratory system & $\begin{array}{l}3.25 \\
(3.40)\end{array}$ & $\begin{array}{l}-0.57 \\
(4.43)\end{array}$ & $\begin{array}{l}3.35 \\
(4.54)\end{array}$ & $\begin{array}{l}-13.80 \\
(9.94)\end{array}$ & $\begin{array}{l}-1.08 \\
(2.08)\end{array}$ & $\begin{array}{l}2.16 \\
(1.46)\end{array}$ & $\begin{array}{l}-0.08 \\
(1.27)\end{array}$ & $\begin{array}{l}0.40 \\
(1.33)\end{array}$ \\
\hline NBW mean & 2.90 & 6.04 & 7.00 & 5.02 & 2.90 & 6.04 & 7.00 & 5.02 \\
\hline Residual category & $\begin{array}{l}17.13 * * \\
(7.56)\end{array}$ & $\begin{array}{l}-1.60 \\
(3.21)\end{array}$ & $\begin{array}{l}20.24^{*} \\
(12.19)\end{array}$ & $\begin{array}{l}-8.81 * * \\
(3.68)\end{array}$ & $\begin{array}{l}9.22 \\
(6.88)\end{array}$ & $\begin{array}{l}1.78 \\
(1.71)\end{array}$ & $\begin{array}{l}-0.51 \\
(2.97)\end{array}$ & $\begin{array}{l}0.62 \\
(2.22)\end{array}$ \\
\hline NBW mean & 10.85 & 9.77 & 11.52 & 12.99 & 10.85 & 9.77 & 11.52 & 12.99 \\
\hline
\end{tabular}

This table summarizes sibling fixed-effects (FE) estimation results for the effects of VLBW and LBW on expenditures on subcategories of medical drugs (ATC classification). Each entry reflects a separate estimation. Expenditures are measured in 2009 euros per year. Standard errors (in parentheses) are robust to clustering at the individual level and to heteroskedasticity of unknown form. *, **, and *** indicate statistical significance at the 10,5, and 1 percent levels, respectively. The estimations also control for the ages of the child and mother, the sex of the child, the number of siblings, birth order, and year fixed effects

physiotherapy, logopedic and phoniatric therapy, and stationary psychotherapy. Finally, we find that LBW children are more likely to contract diseases of the eye and adnexa but are less likely to be diagnosed with neoplasms or to be hospitalized because of injury, poisoning, and certain other consequences of external causes.

Whereas the increase in outpatient expenditures during compulsory schooling is moderate for LBW children (15.62 euros or 8 percent), VLBW children spend 131.16 euros (67 percent) more on outpatient care in this period of life. In contrast to infancy, these cost-increasing effects are predominantly driven by more frequent utilization of services provided by resident doctors. As shown in Table 4, the overwhelming majority of this increase is attributed to greater use of therapists and disabled centers. More is spent for VLBW infants on orthopedic services, physiotherapy, and hippotherapy provided by either disabled centers (37.45 euros; 937 percent) or by resident doctors (31.82 euros; 524 percent). ${ }^{23}$ Although these expenses are lower in absolute terms among school-age children born with LBW, these children also require more services provided by disabled centers (161 percent) and speech therapists (56 percent) than do NBW children.

For school-age children born with VLBW, we also find significant cost-increasing effects for medical drugs. The additional 36.59 euros spent on medication by these children represent an increase of 114 percent. The aforementioned increase in days spent hospitalized for diseases of the nervous system is accompanied by higher consumption of drugs affecting the nervous system. Compared to NBW school-age children, VLBW infants of the same age spend 11.16 euros (336 percent) more on antiepileptics used in the treatment of epileptic seizures and bipolar disorder,

\footnotetext{
23 Another significant cost increase for VLBW newborns was identified for pulmonology services.
} 
Table 6 Days of hospitalization and outpatient expenditures controlling for Apgar scores (FE)

\begin{tabular}{|c|c|c|c|c|c|c|c|c|}
\hline & \multicolumn{4}{|c|}{ Days of hospitalization } & \multicolumn{4}{|c|}{ Outpatient expenditures } \\
\hline & $0-1$ & $2-5$ & $6-14$ & $15-21$ & $0-1$ & $2-5$ & $6-14$ & $15-21$ \\
\hline VLBW & $\begin{array}{l}14.05^{* * * *} \\
(4.60)\end{array}$ & $\begin{array}{l}0.40 \\
(0.29)\end{array}$ & $\begin{array}{l}0.10 \\
(0.12)\end{array}$ & $\begin{array}{l}-0.18 \\
(0.96)\end{array}$ & $\begin{array}{l}395.58 * * \\
(177.10)\end{array}$ & $\begin{array}{l}62.84 * \\
(37.48)\end{array}$ & $\begin{array}{l}112.99 * * * \\
(37.69)\end{array}$ & $\begin{array}{l}-14.51 \\
(49.89)\end{array}$ \\
\hline LBW & $\begin{array}{l}3.93 * * * \\
(1.13)\end{array}$ & $\begin{array}{l}0.16 \\
(0.11)\end{array}$ & $\begin{array}{l}0.13 * * \\
(0.07)\end{array}$ & $\begin{array}{l}0.34 \\
(0.21)\end{array}$ & $\begin{array}{l}124.06^{* * * *} \\
(43.57)\end{array}$ & $\begin{array}{l}39.55 * * * \\
(12.02)\end{array}$ & $\begin{array}{l}13.02 \\
(8.16)\end{array}$ & $\begin{array}{l}15.00 * \\
(9.00)\end{array}$ \\
\hline Apgar score $1 \mathrm{~min}$ & $\begin{array}{l}-0.91 * * * \\
(0.33)\end{array}$ & $\begin{array}{l}-0.060 \\
(0.040)\end{array}$ & $\begin{array}{l}-0.05^{*} \\
(0.03)\end{array}$ & $\begin{array}{l}-0.02 \\
(0.03)\end{array}$ & $\begin{array}{l}-18.47 * * * \\
(7.06)\end{array}$ & $\begin{array}{l}-2.93 \\
(1.93)\end{array}$ & $\begin{array}{l}-4.51 * * * \\
(1.50)\end{array}$ & $\begin{array}{l}-1.12 \\
(1.64)\end{array}$ \\
\hline VLBW & $\begin{array}{l}14.44 * * * \\
(4.72)\end{array}$ & $\begin{array}{l}0.43 \\
(0.34)\end{array}$ & $\begin{array}{l}0.08 \\
(0.20)\end{array}$ & $\begin{array}{l}-0.07 \\
(0.95)\end{array}$ & $\begin{array}{l}408.77 * * \\
(182.92)\end{array}$ & $\begin{array}{l}75.80 * \\
(38.82)\end{array}$ & $\begin{array}{l}117.08 * * * \\
(37.63)\end{array}$ & $\begin{array}{l}-15.37 \\
(49.13)\end{array}$ \\
\hline LBW & $\begin{array}{l}3.89 * * * \\
(1.17)\end{array}$ & $\begin{array}{l}0.17 \\
(0.11)\end{array}$ & $\begin{array}{l}0.14 * * \\
(0.07)\end{array}$ & $\begin{array}{l}0.37 * \\
(0.21)\end{array}$ & $\begin{array}{l}127.87 * * * \\
(44.65)\end{array}$ & $\begin{array}{l}42.37 * * * \\
(12.20)\end{array}$ & $\begin{array}{l}14.51^{*} \\
(8.18)\end{array}$ & $\begin{array}{l}15.04 * \\
(9.13)\end{array}$ \\
\hline Apgar score $5 \mathrm{~min}$ & $\begin{array}{l}-1.05^{* * *} \\
(0.38)\end{array}$ & $\begin{array}{l}-0.07 \\
(0.08)\end{array}$ & $\begin{array}{l}-0.07 \\
(0.06)\end{array}$ & $\begin{array}{l}0.02 \\
(0.04)\end{array}$ & $\begin{array}{l}-10.99 \\
(6.93)\end{array}$ & $\begin{array}{l}1.20 \\
(2.89)\end{array}$ & $\begin{array}{l}-4.30 * \\
(2.50)\end{array}$ & $\begin{array}{l}-1.90 \\
(2.59)\end{array}$ \\
\hline VLBW & $\begin{array}{l}13.61 * * * \\
(4.50)\end{array}$ & $\begin{array}{l}0.38 \\
(0.49)\end{array}$ & $\begin{array}{l}0.127 \\
(0.20)\end{array}$ & $\begin{array}{l}-0.21 \\
(0.97)\end{array}$ & $\begin{array}{l}393.58 * * \\
(176.78)\end{array}$ & $\begin{array}{l}91.27 * * \\
(40.60)\end{array}$ & $\begin{array}{l}116.05 * * * \\
(37.81)\end{array}$ & $\begin{array}{l}-17.22 \\
(48.41)\end{array}$ \\
\hline LBW & $\begin{array}{l}3.79 * * * \\
(1.10)\end{array}$ & $\begin{array}{l}0.17 \\
(0.12)\end{array}$ & $\begin{array}{l}0.15 * * \\
(0.07)\end{array}$ & $\begin{array}{l}0.35 \\
(0.21)\end{array}$ & $\begin{array}{l}124.17 * * * \\
(42.86)\end{array}$ & $\begin{array}{l}44.88 * * * \\
(12.03)\end{array}$ & $\begin{array}{l}14.86^{*} \\
(8.21)\end{array}$ & $\begin{array}{l}13.33 \\
(9.28)\end{array}$ \\
\hline Apgar score $10 \mathrm{~min}$ & $\begin{array}{l}-2.78 * * * \\
(1.05)\end{array}$ & $\begin{array}{l}-0.11 \\
(0.19)\end{array}$ & $\begin{array}{l}-0.07 \\
(0.08)\end{array}$ & $\begin{array}{l}-0.05 \\
(0.07)\end{array}$ & $\begin{array}{l}-42.35^{* *} \\
(20.33)\end{array}$ & $\begin{array}{l}9.03 \\
(5.72)\end{array}$ & $\begin{array}{l}-6.20 \\
(4.59)\end{array}$ & $\begin{array}{l}-3.33 \\
(4.88)\end{array}$ \\
\hline
\end{tabular}

This table summarizes sibling fixed effects estimation results for the effects of VLBW and LBW on days of hospitalization and outpatient expenditures for different age groups, where we also control for the Apgar score. Each panel reflects a separate estimation. Standard errors (in parentheses) are robust to clustering at the individual level and to heteroskedasticity of unknown form. *, **, and *** indicate statistical significance at the 10,5, and 1 percent levels, respectively. The estimations also control for the ages of the child and mother, the sex of the child, the number of siblings, birth order, and year fixed effects

psychoanaleptics (antidepressants, psychostimulants, etc.), and psycholeptics that produce calming effects on the patient. Significantly elevated intake of anti-infectives can still be found among children born with VLBW at this age; however, the effect size of 1.72 euros is substantially lower than that during infancy and early childhood. Finally, we find a significant and quantitatively important increase in expenditures on the residual drug category.

Adolescence and early adulthood

For the oldest individuals in our empirical analysis (aged 15-21 years) who were born at LBW, we find increased levels of both hospitalization ( 0.36 days; 49 percent) and drug expenditures (10.33 euros; 28 percent). The effects on days of hospitalization for LBW teenagers can be attributed to diseases of the respiratory system (see Table 3), whereas the only significantly increased category of medical drugs is those affecting the alimentary tract and metabolism, the expenditures on which increase by 80 percent in comparison to youths and young adults born with NBW. Surprisingly, for people in this age group born with VLBW, we identify cost-decreasing effects for several categories of medical drugs. Young adults born with VLBW spend less on anti-infectives (3.03 euros or 36 percent), drugs for the genitourinary system ( 0.46 euros or 96 percent), and the residual drug category ( 8.81 euros or 68 percent). Although we do not find significant effects on medical attendance at the aggregate level, the disaggregated analysis shows an increase in expenditures at disabled centers (4.81 euros or 676 percent) and on psychiatrists (1.93 euros or 65 percent) among the LBW group. This is evidence that mental problems may persist until early adulthood among LBW children, although we do not observe an accompanying increase in their use of drugs affecting the nervous system. The standard errors during this age category rise considerably compared to the estimates during compulsory schooling; the lack of significant effects with respect to several outcomes among people in this age group born with VLBW may be attributable to the small sample size in this age group. As an alternative, we therefore combine both lower birth weight categories and generate a single group including all newborns with birth weights below 2,500 g (see Tables A.2-A.5). These sensitivity checks suggest that youths and young adults who were born at weights below this threshold spend more days hospitalized because of diseases of the nervous system, spend more on outpatient psychiatric health services, and consume more drugs 
affecting the nervous system. Thus, these teenagers are still at higher risk for mental health problems.

\section{Robustness check: Apgar scores}

As a robustness check, we include Apgar scores in our regressions to illustrate their influence on the outcome variables and also to show how this inclusion would alter the impact of the LBW and VLBW dummies. The Apgar test is a quick and repeatable test to assess the health of newborns. It is performed 1, 5, and $10 \mathrm{~min}$ after birth. The test is done by a doctor, midwife, or nurse who examines the baby's breathing effort, heart rate, muscle tone, reflexes, and skin color. Each category is scored with zero, one or two points resulting in a total score of zero-ten (perfect health condition). Given that the correlation between the three Apgar scores lies in a range between 0.54 and 0.75 , we include them separately in our regressions to avoid problems of multicollinearity. We therefore present three regressions for each output in Table 6.

As can be seen from the estimation results, the Apgar scores have a significantly negative impact on both expenditures and days of hospitalization for the age group $0-1$, whereas this effect vanishes for the older age groups. Moreover, the inclusion of Apgar scores only slightly changes the coefficients for LBW and VLBW in almost all specifications, and the overall pattern discussed above remains.

An increase in the Apgar 1 score by one point decreases outpatient expenditures for the age group $0-1$ by 18.47 euros. If we instead control for Apgar 10, the same increase in the score by one point would decrease outpatient health expenditures for the youngest age group by 42.35 euros, whereas the coefficient of Apgar 5 remains statistically insignificant. The effects of the Apgar scores on outpatient expenditures for older age groups are not statistically significant with the exception of age group 6-14 whose expenditures decrease by 4.51 (4.30) euros, which is associated with a one point increase in the score of Apgar 1 (Apgar 5). The coefficients for LBW and VLBW remain almost unchanged as compared to our baseline specification in Table 2. Overall, the quantitative effects of the birth weight dummies decrease somewhat, and most significance levels remain the same.

The pattern for the estimation of hospital days is similar. We find a significantly negative impact of Apgar scores on the days of hospitalization for the youngest age group in a range between 0.91 and 2.78 days. With a single exception (Apgar 1 in age group 6-14), ${ }^{24}$ the inclusion of Apgar scores has no significant impact on days of hospitalization for infants older than 2 years. Finally, as compared to our baseline specification in Table 2, the inclusion of the Apgar

\footnotetext{
${ }^{24}$ This effect is, however, quantitatively of minor importance.
}

score has no remarkable influence on the effects of LBW and VLBW on days of hospitalization. Summarizing the results of this robustness check, we find that the effects of LBW and VLBW persist over the age groups, whereas the impact of Apgar scores dissipates during childhood and adolescence [7, 30].

\section{Discussion}

As expected, our analysis reveals that the largest effects of LBW and VLBW on health-care utilization occur in the first year of life, with particularly pronounced impacts on the number of days spent hospitalized and the consumption of medical drugs. The increased intake of medical drugs is predominantly driven by anti-infectives, an effect explained by the fact that the immune systems of these newborns are not yet fully developed [29]. Consequently, the administration of these drugs prevents those infants from contracting infectious diseases. Although the effects of birth weight on aggregate outcomes decline with age, suggesting that children of lower birth weights catch up to others over time, some differences persist. The disaggregated analyses suggest that LBW mainly affects physical health in infancy and early childhood. During compulsory schooling, we find the first evidence that the cognitive development of these children may be retarded. This conclusion is supported by four facts: (1) LBW children are more likely to be hospitalized for mental and behavioral disorders, (2) their intake of drugs affecting the nervous system is substantially elevated, (3) these children have a higher rate of treatment by speech therapists, and (4) VLBW children receive more ergo- and hippotherapy. Drugs affecting the nervous system include preparations including the active ingredient methylphenidate (e.g., Ritalin). The consumption of this medication, therefore, suggests that children who consume this medication are more likely to suffer from mental disorders, such as attention deficit hyperactivity disorder (ADHD), which become noticeable when they enroll in school. This result is in line with the findings of Linnet et al. [23], who show that premature or LBW babies are at much higher risk of contracting ADHD. Together with the fact that we observe cost-increasing effects for psychiatric services in adolescence, we conclude that LBW predominantly affects mental health in the medium and long terms. ${ }^{25}$

Using data from the US and Canada, Currie and Stabile [15] show that behavior problems at age 4-11, particularly

\footnotetext{
25 The increased consumption of drugs affecting the alimentary tract and metabolism and increased hospitalization rates for diseases of the respiratory system in age group 15-21 suggest that LBW children also have a higher risk of suffering from physical health maladies in adolescence and early adulthood.
} 
ADHD, have large negative effects on future education outcomes. Moreover, Currie et al. [16] demonstrate that the diagnosis of ADHD at school entry age is correlated with poorer future outcomes (welfare participation and educational outcomes), even if children have no other mental health service utilization at later ages. This implies that the presented results may translate into persistent negative effects for LBW children. The negative correlation between LBW and socioeconomic status in later life may be at least partially caused by mental health problems that decrease the performance of the affected children in school.

Since OLS results may be subject to omitted-variable bias if unobserved covariates correlate with outcome and birth weight, we estimate sibling fixed effects to control for time-invariant heterogeneity at least. Obviously, if there is any unobserved time-variant variable that correlates with birth weight and outcome, a sibling fixed effects estimation fails to identify the true causal effects. Black et al. [10] show that the bias in their OLS estimates of adult outcomes in terms of height, IQ, earnings, and education is much smaller than that for short-term outcomes. This can be explained by the fact that omitted variables (e.g., the smoking behavior of mothers) are more strongly correlated with short- than with long-term outcomes. Accordingly, we also find that the bias between the OLS and fixed-effects results decreases with age. Our results demonstrate that the bias decreases starting in the second year of life, not just during adulthood. Omitted variables such as maternal smoking behavior seem to affect children strongly in utero, but their negative consequences may diminish early in life, as (unobserved) maternal characteristics become less important as the children age.

\section{Conclusions}

The strong effects of LBW and VLBW during the first year of life and their reduction in size with age are compatible with the view that parents of children born at LBW and VLBW undertake health-improving medical investments that mitigate the negative consequences of the poor initial health endowments of their newborns. This analysis reveals that almost all differences in physical health between individuals born weighing less than 2,500 $\mathrm{g}$ and their NBW counterparts disappear by early adulthood. ${ }^{26}$ To the contrary, we provide evidence that differences in terms of diseases of the nervous system and the associated medical services and medication intake persist until early

\footnotetext{
26 This analysis does not allow for judgment of potential long-term health effects that stay latent until later in adulthood, as discussed by Almond and Currie [4]. For a review of the intergenerational effects of fetal programming with respect to cardiovascular risk, see, e.g., Drake and Walker [17].
}

adulthood. From a policy perspective, the best solution would be to prevent LBW and particularly VLBW. To that end, further efforts in counseling for expectant mothers on the determinants and risk factors of VLBW and LBW may offer a promising avenue for reduction in their incidence. Although the behavior of the mother strongly influences the health of her children, environmental factors also affect conditions in utero. Since smoking is one of the most important amendable risk factors for VLBW and LBW, public smoking bans that aim to reduce exposure to secondhand smoke seem to be of particular importance.

Given that it is unrealistic to prevent VLBW and LBW entirely, access to and uptake of necessary medical treatments need to be guaranteed in order to mitigate the negative consequences. Nevertheless, in addition to the requirement of access to health services, children can receive appropriate treatment only if their health conditions are correctly diagnosed. Parents, however, might not properly interpret certain behaviors and symptoms shown by their children that indicate health problems. Therefore, a postnatal screening program specially tailored to these children may represent an effective way to identify children who need further interventions. Since the benefits of medical and therapeutic interventions are expected to be large if they are delivered early in life [3, 18, 19], a postnatal screening program tailored to these infants could be integrated in the already existing Austrian mother-child care program. Positive effects for a program targeted at infants born at LBW have, for instance, been demonstrated for the Infant Health and Development Program [11, 24, 25]. Consequently, we argue for pre-school screenings to mitigate the consequences of negative conditions during pregnancy with a focus on latent mental health problems and behavioral disorders.

Acknowledgments We would like to thank Wolfgang Frimmel, Martin Halla, Martina Zweimüller, the participants at the 2011 Annual Conference of the Austrian Public Health Society, and the participants at the policy workshop of the National Research Network (NRN) entitled "Labor Economics and the Welfare State in Vienna" (2011) for their helpful discussions and comments. The usual disclaimer applies. Moreover, we thank the Upper Austrian Sickness Fund for providing us with data. Financial support was provided by the Austrian Science Fund (FWF) under project no. S10306-G14.

\section{References}

1. Aarnoudse-Moens, C.H., Weisglas-Kuperus, N., van Goudoever, J.B., Oosterlaan, J.: Meta-analysis of neurobehavioral outcomes in very preterm and/or very low birth weight children. Pediatrics 124(2), 717-728 (2009)

2. Alexander, G.R., Korenbrot, C.C.: The role of prenatal care in preventing low birth weight. Future Child 5(1), 103-120 (1995) 
3. Almond, D., Currie, J.: Human Capital Development Before Age Five, Vol. 4 of Handbook of Labor Economics, Chap. 15. Elsevier, Amsterdam , pp. 1315-1486 (2011a)

4. Almond, D., Currie, J.: Killing me softly: the fetal origins hypothesis. J. Econ. Perspect. 25(3), 153-172 (2011b)

5. Almond, D., Chay, K.Y., Lee, D.S.: The costs of low birth weight. Q. J. Econ. 120(3), 1031-1083 (2005)

6. Ashdown-Lambert, J.R.: A review of low birth weight: predictors, precursors and morbidity outcomes. J. R. Soc. Promot. Health 125(2), 76-83 (2005)

7. Behnke, M., Eyler, F.D., Carter, R.L., Hardt, N.S., Cruz, A.C., Resnick, M.B.: Predictive value of Apgar scores for developmental outcome in premature infants. Am. J. Perinatol. 6(1), 18-21 (1989)

8. Behrman, J.R., Rosenzweig, M.R.: Returns to birthweight. Rev. Econ. Stat. 86(2), 586-601 (2004)

9. Bennet, N.G., Conley, D.: Is biology destiny? Birth weight and life chances. Am. Sociol. Rev. 65, 458-467 (2000)

10. Black, S.E., Devereux, P.J., Salvanes, K.G.: From the cradle to the labor market - the effect of birth weight on adult outcomes. Q. J. Econ. 122(1), 409-439 (2007)

11. Brooks-Gunn, J., McCarton, C.M., Casey, P.H., McCormick, M.C., Bauer, C.R., Bernbaum, J.C., Tyson, J., Swanson, M., Bennett, F.C., Scott, D.T.: Early intervention in low-birth-weight premature infants. Results through age 5 years from the infant health and development program. J. Am. Med. Assoc. 272(16), 1257-1262 (1994)

12. Conley, D., Strully, K.W., Bennett, N.G.: Twin differences in birth weight: the effects of genotype and prenatal environment on neonatal and post-neonatal mortality. Econ. Hum. Biol. 4(2), 151-183 (2006)

13. Currie, J.: Healthy, wealthy and wise: socioeconomic status, poor health in childhood, and human capital development. J. Econ. Lit. 47(1), 87-122 (2009)

14. Currie, J., Moretti, E.: Biology as destiny? Short- and long-term determinants of intergenerational transmission of birth weight. J. Labor Econ. 25(2), 231-264 (2007)

15. Currie, J., Stabile, M.: Mental health in childhood and human capital. In: Gruber, J. (ed.) The Problems of Disadvantaged Youth: An Economic Perspective, pp. 115-148. University of Chicago Press, Chicago (2009)

16. Currie, J., Stabile, M., Manivong, P., Roos, L.L.: Child health and young adult outcomes. J. Hum. Resour. 45(3), 517-548 (2010)

17. Drake, A.J., Walker, B.R.: The intergenerational effects of fetal programming: non-genomic mechanisms for the inheritance of low birth weight and cardiovascular risk. J. Endocrinol. 180, 1-16 (2004)
18. Heckman, J., Moon, S.H., Pinto, R., Savelyev, P., Yavitz, A.: Analyzing social experiments as implemented: a reexamination of the evidence from the HighScope Perry Preschool Program. Quant. Econ. Econom. Soc. 1(1), 1-46 (2010a)

19. Heckman, J., Moon, S.H., Pinto, R., Savelyev, P., Yavitz, A.: The rate of return to the HighScope Perry Preschool Program. J. Public Econ. 94(1-2), 114-128 (2010b)

20. Johnson, R.C., Schoeni, R.F.: The influence of early-life events on human capital, health status, and labor market outcomes over the life course. B.E. J. Econ. Anal. Policy Adv. 11(3), 2521-2575 (2010)

21. Kramer, M.S.: Determinants of low birth weight: methodological assessment and meta-analysis. Bull. World Health Organ. 65(5), 663-737 (1987a)

22. Kramer, M.S.: Intrauterine growth and gestational duration determinants. Pediatrics 80(1), 502-211 (1987b)

23. Linnet, K.M., Wisborg, K., Agerbo, E., Secher, N.J., Thomsen, P.H., Henriksen, T.B.: Gestational age, birth weight, and the risk of hyperkinetic disorder. Arch. Dis. Child. 91(8), 655-660 (2006)

24. McCarton, C.M., Brooks-Gunn, J., Wallace, I.F., Bauer, C.R., Bennett, F.C., Bernbaum, J.C., Broyles, R.S., Casey, P.H., McCormick, M.C., Scott, D.T., Tyson, J., Tonascia, J., Meinert, C.L.: Results at age 8 years of early intervention for low-birthweight premature infants. The infant health and development program. J. Am. Med. Assoc. 277(2), 126-132 (1997)

25. McCormick, M.C., Brooks-Gunn, J., Buka, S.L., Goldman, J., Yu, J., Salganik, M., Scott, D.T., Bennett, F.C., Kay, L.L., Bernbaum, J.C., Bauer, C.R., Martin, C., Woods, E.R., Martin, A., Casey, P.H.: Early intervention in low birth weight premature infants: results at 18 years of age for the infant health and development program. Pediatrics 117, 771-780 (2006)

26. Oreopoulos, P., Stabile, M., Walld, R., Roos, L.L.: Short-, medium-, and long-term consequences of poor infant health-an analysis using siblings and twins. J. Hum. Resour. 43(1), 88-138 (2008)

27. Pojda, J., Kelley, L.: Low birthweight, nutrition policy paper 18. Administrative Committee on Coordination/Sub-Committee on Nutrition (2000)

28. Royer, H.: Separated at girth: US twin estimates of the effects of birth weight. Am. Econ. J. Appl. Econ. 1(1), 49-85 (2009)

29. Saari, T.N.: Immunization of preterm and low birth weight infants. Pediatrics 112(1), 193-198 (2003)

30. Shah, S., Zemichael, O., Meng, H.D.: Factors associated with mortality and length of stay in hospitalised neonates in Eritrea, Africa: a cross-sectional study. Br. Med. J. Open 2, 1-9 (2012) 